\title{
HIV-infected individuals receiving effective antiviral therapy for extended periods of time continually replenish their viral reservoir
}

\author{
Tae-Wook Chun, ${ }^{1}$ David C. Nickle, ${ }^{2}$ J. Shawn Justement, ${ }^{1}$ Danielle Large, ${ }^{1}$ Alice Semerjian, ${ }^{1}$ \\ Marcel E. Curlin, ${ }^{2}$ M. Angeline O'Shea, ${ }^{1}$ Claire W. Hallahan, ${ }^{3}$ Marybeth Daucher, ${ }^{1}$ Douglas J. Ward, ${ }^{4}$ \\ Susan Moir, ${ }^{1}$ James I. Mullins, ${ }^{2}$ Colin Kovacs, ${ }^{5}$ and Anthony S. Fauci ${ }^{1}$

\begin{abstract}
'Laboratory of Immunoregulation, National Institute of Allergy and Infectious Diseases, NIH, Bethesda, Maryland, USA. ${ }^{2}$ Department of Microbiology, Maryland, USA. ${ }^{4}$ Dupont Circle Physicians Group, Washington, DC, USA. ${ }^{5}$ Department of Medicine, University of Toronto, Toronto, Ontario, Canada.
\end{abstract} \\ University of Washington, Seattle, Washington, USA. ${ }^{3}$ Biostatistical Research Branch, National Institute of Allergy and Infectious Diseases, NIH, Bethesda,
}

\begin{abstract}
The persistence of latently infected, resting $\mathrm{CD}^{+} \mathrm{T}$ cells is considered to be a major obstacle in preventing the eradication of HIV-1 even in patients who have received effective antiviral therapy for an average duration of 5 years. Although previous studies have suggested that the latent HIV reservoir in the resting $\mathrm{CD}^{+} \mathrm{T}$ cell compartment is virologically quiescent in the absence of activating stimuli, evidence has been mounting to suggest that low levels of ongoing viral replication persist and in turn, prolong the overall half-life of HIV in patients receiving antiviral therapy. Here, we demonstrate the persistence of replication-competent virus in $\mathrm{CD}^{+} \mathrm{T}$ cells in a cohort of patients who had received uninterrupted antiviral therapy for up to 9.1 years that rendered them consistently aviremic throughout that time. Surprisingly, substantially higher levels of HIV proviral DNA were found in activated $\mathrm{CD}^{+} \mathrm{T}$ cells when compared with resting $\mathrm{CD} 4^{+} \mathrm{T}$ cells in the majority of patients we studied. Phylogenetic analyses revealed evidence for cross infection between the resting and activated $\mathrm{CD}^{+} \mathrm{T}$ cell compartments, suggesting that ongoing reactivation of latently infected, resting $\mathrm{CD} 4^{+}$ $T$ cells and spread of virus by activated $\mathrm{CD}^{+} \mathrm{T}$ cells may occur in these patients. Such events may allow continual replenishment of the $\mathrm{CD}^{+} \mathrm{T}$ cell reservoir and resetting of the half-life of the latently infected, resting $\mathrm{CD4}^{+} \mathrm{T}$ cells despite prolonged periods of aviremia.
\end{abstract}

\section{Introduction}

The use of effective antiviral therapy has led to rapid and sustained suppression of HIV replication and has dramatically improved the clinical outcome in a majority of infected individuals (1). However, it has not been possible to eradicate HIV in infected individuals receiving effective antiviral therapy mainly due to the persistence of various viral reservoirs (2-5). Among these, a pool of latently infected cells in the resting $\mathrm{CD}^{+} \mathrm{T}$ cell compartment has been one of the most extensively studied to date and is considered to be a major impediment to HIV eradication $(2-4,6,7)$. In this regard, it has been suggested that the extremely long intrinsic half-life of such a latent HIV reservoir makes eradication of the virus all but impossible in infected individuals receiving effective antiviral therapy even after more than 5 years of uninterrupted treatment (5). Of note, HIV that resides in infected, resting $\mathrm{CD}^{+} \mathrm{T}$ cells has been shown to be virologically quiescent and lacking the ability to produce multiply spliced HIV RNA or viral particles (8). However, a number of studies over the past several years have suggested that low levels of ongoing viral replication continue to persist and consequently prolong the overall half-life of HIV in patients receiving antiviral therapy (9-12). These include the persistence of replication-competent virus (2-4), unintegrated proviral DNA, both linear (2) and circularized $(13,14)$, and cell-associated HIV RNA $(6,7,11,15,16)$. In addition, other studies have demonstrated that intensification of conventional antiviral regimens in patients who remained aviremic accelerated the

Conflict of interest: The authors have declared that no conflict of interest exists. Citation for this article: J. Clin. Invest. 115:3250-3255 (2005). doi:10.1172/JCI26197. decay of the latent HIV reservoir in the resting $\mathrm{CD}^{+}{ }^{+} \mathrm{T}$ cell compartment (12) and further suppressed plasma viremia to well below the limit of detection (3.2-23 copies of HIV RNA per ml) (17). These findings suggest that low levels of ongoing HIV replication continue to persist and may contribute to the longevity of the latent viral reservoir by continually fueling new rounds of infection in resting $\mathrm{CD}^{+} \mathrm{T}$ cells. Nonetheless, the source(s) and extent of ongoing viral replication in compartments other than resting $\mathrm{CD}^{+} \mathrm{T}$ cells in patients receiving effective antiviral therapy for extended periods of time (greater than 5 years) have yet to be fully delineated.

In the present study, we investigate the presence and status of residual HIV in patients who had received effective antiviral therapy for up to 9.1 years and examine the underlying mechanisms by which HIV persists in $\mathrm{CD}^{+} \mathrm{T}$ cells of such individuals. We demonstrate that all infected subjects studied carried replication-competent HIV in their $\mathrm{CD} 4^{+} \mathrm{T}$ cells and the majority of patients harbored considerable levels of HIV proviral DNA in their activated as well as resting $\mathrm{CD}^{+} \mathrm{T}$ cell compartments. Finally, we also provide evidence for cross infection between these 2 compartments, suggesting a possible mechanism by which HIV persists in patients who are receiving clinically effective antiretroviral therapy.

\section{Results}

We studied a cohort of patients who had received uninterrupted antiviral therapy for up to 9.1 years (average of 8.3 years) and who were selected on the basis of having maintained undetectable levels of plasma viremia ( $<500$ or $<50$ copies of HIV RNA per ml plasma) for the entire time on therapy prior to enrollment (Table 1 and Figure 1). We first determined the frequency of $\mathrm{CD}^{+} \mathrm{T}$ cells carrying 
Table 1

Profiles of HIV-infected patients

\begin{tabular}{lccccc} 
Subject & $\begin{array}{c}\text { CD4 count } \\
\text { at time of study } \\
\text { (cells/ul) }\end{array}$ & $\begin{array}{c}\text { CD8 count } \\
\text { at time of study } \\
\text { (cells/ul) }\end{array}$ & $\begin{array}{c}\text { Plasma HIV RNA } \\
\text { at time of study } \\
\text { (copies/ml) }\end{array}$ & $\begin{array}{c}\text { Antiviral therapy } \\
\text { at time of study }\end{array}$ & $\begin{array}{c}\text { Duration } \\
\text { of therapy } \\
\text { (yr) }\end{array}$ \\
1 & 1220 & 520 & $<50$ & AZT, 3TC, SQV, LPV/r & 9.1 \\
2 & 516 & 382 & $<50$ & ABC, TDF, NVP & 8.3 \\
3 & 573 & 406 & $<50$ & ABC, TDF, NVP & 8.9 \\
4 & 330 & 550 & $<50$ & AZT, 3TC, NFV & 7.6 \\
5 & 610 & 600 & $<50$ & ABC, 3TC, NVP & 8.1 \\
6 & 980 & 1170 & $<50$ & 3TC, TDF, NVP & 8.0 \\
7 & 520 & 610 & $<50$ & 3TC, TDF, EFV, LPV/r & 8.0 \\
8 & 662 & 772 & $<50$ & AZT, 3TC, EFV & 8.6 \\
9 & 560 & 1230 & $<50$ & ABC, 3TC, EFV, LPV/r & 8.0 \\
10 & 605 & 670 & $<50$ & ABC, TDF, EFV & 8.7 \\
11 & 280 & 490 & $<50$ & AZT, 3TC, SQV, RTV & 8.3 \\
Mean & 623 & 673 & & & 8.3 \\
\hline
\end{tabular}

AMeasured by ultrasensitive bDNA or RT-PCR assay with a detection limit of 50 copies per $\mathrm{ml}$ of plasma. ${ }^{\mathrm{B}} \mathrm{Drugs}$ used in antiviral regimens included the nucleoside analogs zidovudine (AZT), lamivudine (3TC), abacavir (ABC), and tenofovir (TDF); the nonnucleoside reverse transcriptase inhibitors efavirenz (EFV) and nevirapine (NVP); and the protease inhibitors lopinavir/ritonavir (LPV/r), nelfinavir (NFV), ritonavir (RTV), and saquinavir (SQV).

resting and activated $\mathrm{CD}^{+}$ $\mathrm{T}$ cells were cultured for 24 hours in the absence of any activating stimuli. We have previously demonstrated that resting $\mathrm{CD}^{+} \mathrm{T}$ cells from aviremic patients do not spontaneously release any measurable levels of virus in the absence of activating stimuli (18). Consistent with our previous findings, the resting $\mathrm{CD}^{+} \mathrm{T}$ cells of infected individuals described herein, having received long-term effective antiviral therapy, did not produce any detectable levels of virions during the short incubation period (Figure 3B). However, the activated $\mathrm{CD}^{+} \mathrm{T}$ cells of 6 of 8 patients examined spontaneously released detectable

replication-competent virus in the study subjects. The persistence of replication-competent virus in resting $\mathrm{CD}^{+} \mathrm{T}$ cells is well documented in patients who have been on effective antiviral therapy for an average duration of 5 years (5). However, such an analysis has not been systematically carried out in patients who have received effective antiviral therapy for longer than 5 years. In all patients examined, purified $\mathrm{CD} 4^{+} \mathrm{T}$ cells from PBMCs carried replicationcompetent HIV (median 0.059 infectious units $/ 1 \times 10^{6}$ cells, range 0.006-0.322; Figure 2), indicating that none of the study participants had eradicated HIV infection despite having received years of continuous and effective antiviral therapy.

In order to further investigate the presence and status of residual HIV in patients who received effective antiviral therapy for extended periods of time and to delineate the underlying mechanisms by which HIV persists in the $\mathrm{CD}^{+}$ $T$ cells of such individuals, we measured various virologic markers in highly purified resting and activated $\mathrm{CD}^{+} \mathrm{T}$ cells. Highly purified $(>99.0 \%)$ FACS-enriched resting (CD25-CD69-HLA-DR-) and activated $\left(\mathrm{CD} 25^{+} \mathrm{CD} 69^{+} \mathrm{HLA}-\mathrm{DR}^{+}\right) \mathrm{CD}^{+} \mathrm{T}$ cells were subjected to quantitative real-time PCR specific for detection of HIV DNA. As shown in Figure 3A, HIV proviral DNA was found in both compartments with the frequency of cells carrying HIV proviral DNA in the activated $\mathrm{CD}^{+} \mathrm{T}$ cell compartment (median 980 copies, range $292-3180 / 1 \times 10^{6}$ cells) being significantly higher than in the resting $\mathrm{CD}^{+} \mathrm{T}$ cell compartment (median 589 copies, range $66-1751 / 1 \times 10^{6}$ cells; $P=0.01$ ). Thus, in all patients examined, the presence of HIV in resting as well as activated $\mathrm{CD}^{+}{ }^{+} \mathrm{T}$ cells was sustained despite extended periods of undetectable HIV plasma viremia.

In order to determine whether the HIV proviral DNA detected in the patients was capable of generating virions, microbead-enriched
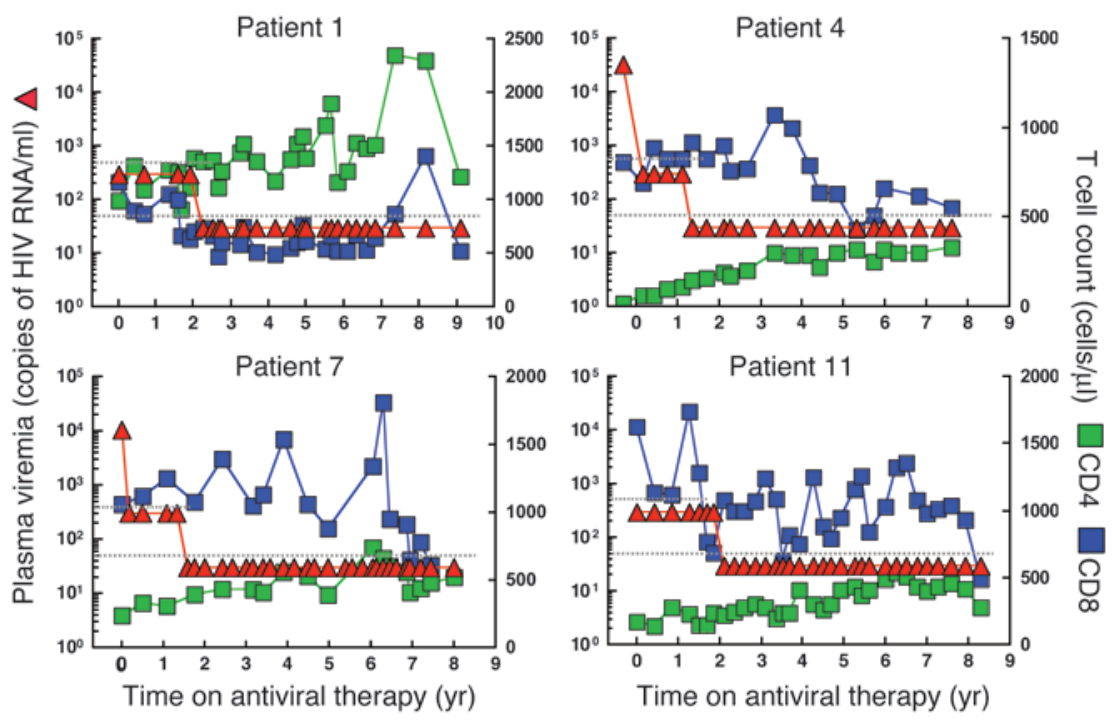

Figure 1

Plasma viremia and $\mathrm{CD}^{+}$and $\mathrm{CD} 8^{+} \mathrm{T}$ cell counts of 4 representative study participants. The dotted lines indicate the limit of detection of plasma viremia ( $<500$ or $<50$ copies of HIV RNA per $\mathrm{ml})$. 


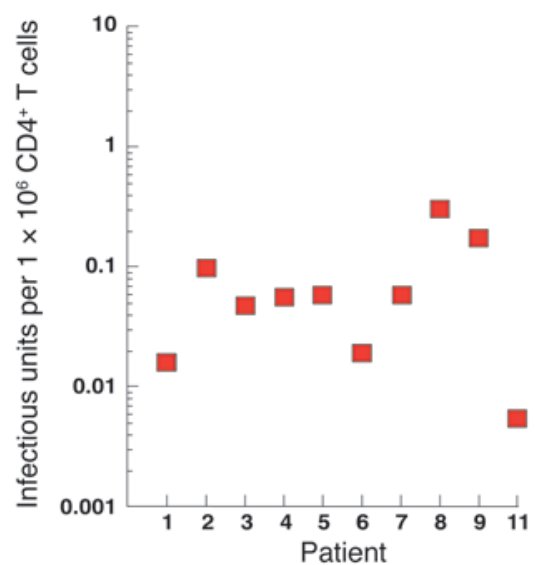

Figure 2

Frequency of replication-competent HIV in CD4+ $\mathrm{T}$ cells of infected individuals receiving effective antiviral therapy for prolonged periods of time. The frequency of cells carrying infectious HIV ( $y$ axis) was assessed by activation of purified CD4+ $T$ cells from the patients studied ( $x$ axis) with replicates of $1 \times 10^{6} \mathrm{CD}^{+}+\mathrm{T}$ cells per well in 12-well plates.

tion onto the branches of maximum-likelihood trees were performed on the sequences obtained (23). As illustrated in Figure 4A, evidence for bidirectional HIV infection between the resting and activated $\mathrm{CD}^{+} \mathrm{T}$ cell compartments was observed in the phylogenetic trees. The calculation of the number of HIV migration events also indicated that viral migration was occurring from activated to resting $\mathrm{CD}^{+} \mathrm{T}$ cells (Figure 4B). Considering that activated $\mathrm{CD} 4{ }^{+}$ $\mathrm{T}$ cells are the main source of productive $\operatorname{HIV}$ replication $(24,25)$ and our finding that only activated $\mathrm{CD} 4^{+} \mathrm{T}$ cells produced virions after overnight culture (Figure 3B), these data suggest evidence for spread of infection by productively infected cells. However, our data also suggest migration of HIV from infected, resting $\mathrm{CD}^{+} \mathrm{T}$ cells toward activated $\mathrm{CD} 4^{+} \mathrm{T}$ cells (Figure $4 \mathrm{~B}$ ), presumably as a result of reactivation of latently infected, resting $\mathrm{CD} 4^{+} \mathrm{T}$ cells that occurred in infected individuals despite undetectable plasma viremia.

\section{Discussion}

In the present study, we investigated the source(s) and the extent of residual HIV replication and examined the underlying mechanisms by which HIV persists in $\mathrm{CD}^{+} \mathrm{T}$ cells of patients who received effective antiviral therapy for extended periods of time. We demonstrated that all infected subjects examined carried repli-

\section{Figure 3}

Persistence of HIV in resting and activated CD4+ $T$ cells of infected individuals receiving effective antiviral therapy for prolonged periods of time. (A) Frequency of FACS-sorted resting and activated CD4 ${ }^{+} \mathrm{T}$ cells carrying HIV proviral DNA. The median values are shown as black bars. (B) Levels of cellfree virions released by resting and activated $\mathrm{CD} 4^{+} \mathrm{T}$ cells in overnight cultures in the absence of activating stimuli. Cell-free supernatants from each culture harvested after 1 day of culture were subjected to the Amplicor HIV-1 test (detection limit of 50 copies of HIV RNA per $\mathrm{ml}$ ). cation-competent HIV in their $\mathrm{CD} 4^{+} \mathrm{T}$ cells despite having received clinically effective antiviral therapy for extended periods of time ( 8.3 years on average). To our knowledge, this is the first study to examine levels of replication-competent HIV in the $\mathrm{CD}^{+} \mathrm{T}$ cell compartments of patients who have received effective antiviral therapy for such long periods of time (up to 9.1 years). We also demonstrated that, contrary to current dogma, it is the activated $\mathrm{CD}^{+} \mathrm{T}$ cell compartment that harbors the majority of persisting $\mathrm{HIV}$ in infected individuals who have had no detectable viremia for extended periods of time as a result of effective antiretroviral therapy. In the years following the first indications of HIV latency in infected individuals $(26,27)$, the vast majority of studies, if not all, addressing the persistence of HIV in the era of effective antiviral therapy focused heavily on the latent viral reservoir in the resting $\mathrm{CD}^{+} \mathrm{T}$ cell compartment as a major impediment to eradication of $\operatorname{HIV}(2,3,9,28-31)$. However, the activated $\mathrm{CD}^{+} \mathrm{T}$ cell compartment has not been fully explored as a potential viral reservoir in infected individuals receiving clinically successful antiviral therapy mainly because it has been believed that such cells are short lived and not expected to harbor virus (25). By demonstrating the presence of HIV in activated CD4 ${ }^{+} \mathrm{T}$ cells of maximally suppressed individuals, we thus provide compelling evidence for contribution of this compartment to the continual reseeding of HIV reservoirs. Although mitotic division of activated $\mathrm{CD} 4^{+} \mathrm{T}$ cells harboring defective virus could account for the higher frequency of cells carrying HIV proviral DNA in activated $\mathrm{CD}^{+} \mathrm{T}$ cell compartments compared with resting $\mathrm{CD}^{+} \mathrm{T}$ cell compartments, the evidence presented herein for spontaneous release of virions and viral migration and the short half-life of activated $\mathrm{CD}^{+} \mathrm{T}$ cells would argue for the persistence of infectious virus in activated $\mathrm{CD} 4^{+} \mathrm{T}$ cells.

The present study offers a plausible mechanism to explain the persistence of HIV in infected individuals receiving effective antiviral therapy resulting in prolonged periods of aviremia. Our phylogenetic data suggest that latently infected, resting $\mathrm{CD}^{+} \mathrm{T}$ cells may become reactivated, most likely as a result of normal immunologic responses to various recall antigens or routine vaccination (32) and induction of cytokines (33). In turn, virions released during the reactivation process may spread to and infect neighboring resting as well as activated $\mathrm{CD}^{+}{ }^{+} \mathrm{T}$ cells; direct cell-to-cell spread in the absence of virion release may also occur. In this regard, the presence of unintegrated HIV DNA in resting $\mathrm{CD}^{+}{ }^{+} \mathrm{T}$ cells $(2)$ and circularized HIV DNA in CD4 $4^{+} \mathrm{T}$ cells $(13,14)$ has been demonstrated
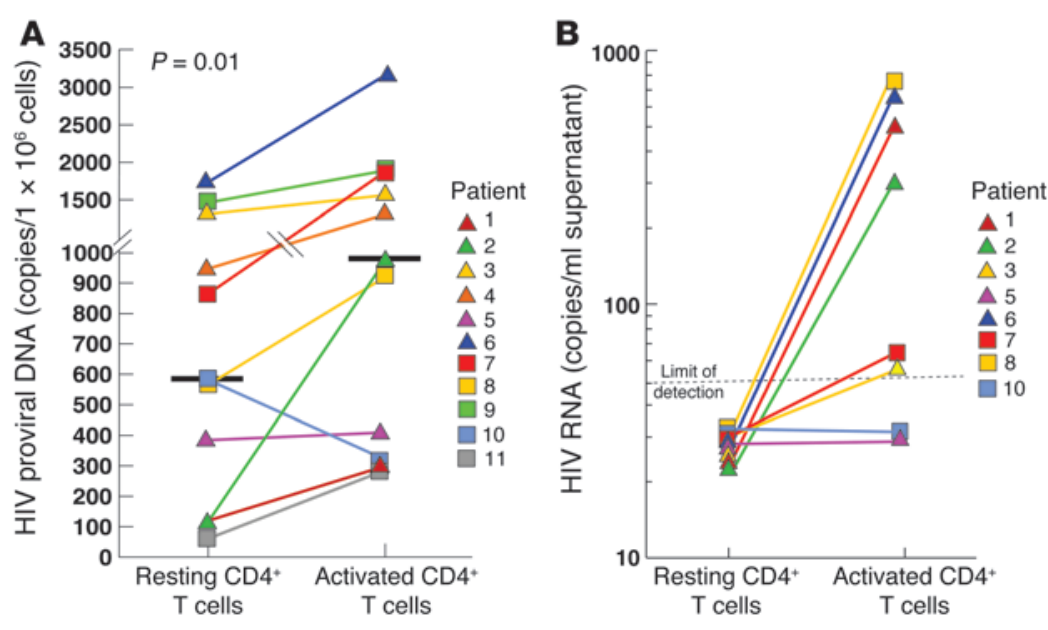
A Patient 2

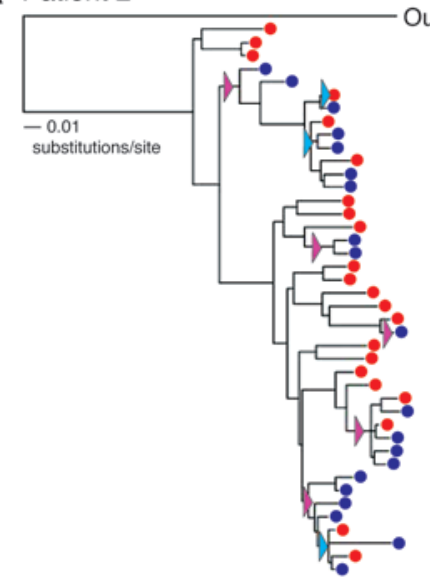

Patient 7

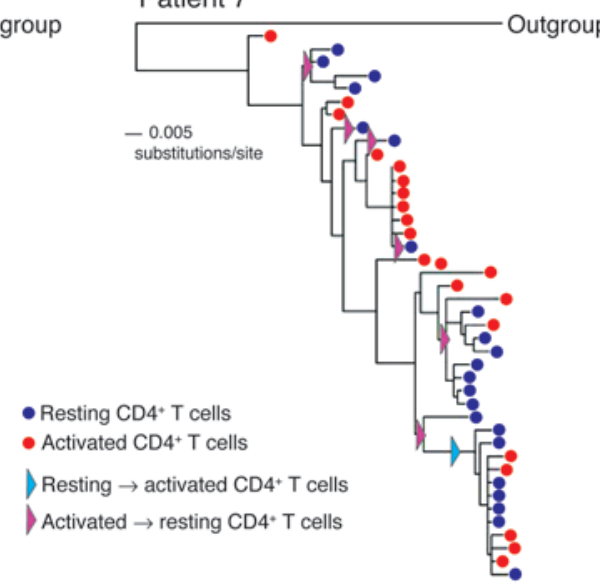

$\mathbf{B}$

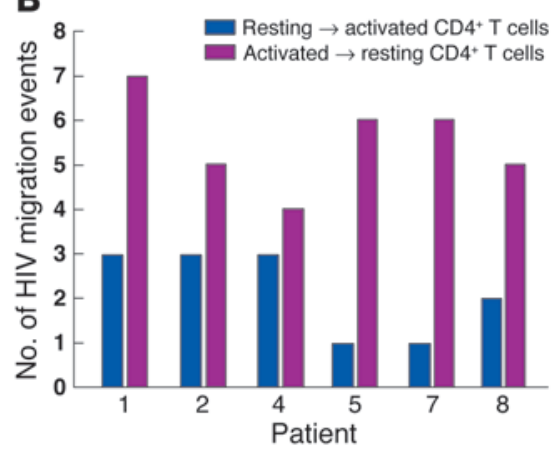

Figure 4

Phylogenetic analysis of HIV env DNA and evidence for cross infection between resting and activated CD4+ $T$ cells in patients receiving effective antiviral therapy. (A) Phylogenetic trees of HIV env sequences in resting (blue circles) and activated (red circles) CD4+ T cells of 2 representative patients. The outgroup sequences were obtained from unrelated HIV-infected patients. The direction of HIV migration from activated to resting (pink arrow) and from resting to activated (blue arrow) CD4+ $\mathrm{T}$ cells is shown. The bar indicates genetic distance. (B) The number of viral migration events observed on the phylogenetic trees within the resting and activated CD4 ${ }^{+} \mathrm{T}$ cell compartments is shown.

in patients receiving effective antiviral therapy, indicating recent infection. Although the half-life of integrated HIV DNA in resting $\mathrm{CD}^{+} \mathrm{T}$ cells has been firmly demonstrated to exceed the previous estimates (5), the reactivation events described above could allow continual replenishment of the $\mathrm{CD}^{+} \mathrm{T}$ cell viral reservoir and reset the overall half-life of HIV in infected patients receiving effective therapy. We also provide evidence for migration of virus from activated to resting $\mathrm{CD} 4^{+} \mathrm{T}$ cells, although it should be noted that our findings do not exclude other viral reservoirs as sources of infectious HIV. In addition, while these findings were based on cross-sectional phylogenetic analyses of viral DNA, the presence of HIV in activated $\mathrm{CD}^{+} \mathrm{T}$ cells, a population thought to have a relatively short half-life (25), strongly suggests that viral migration events noted in our study were relatively recent and involved infectious virions. Indeed, highly enriched activated $\mathrm{CD}^{+} \mathrm{T}$ cells from the majority of patients we examined spontaneously released virus in the overnight culture in the absence of any activating stimuli, further strengthening the above observation. In addition, the persistence of virus in this cellular compartment may be responsible for prompt rebound of plasma virus upon cessation of effective antiviral therapy in infected individuals $(9,29,30)$.

The eradication of HIV by antiretroviral therapy has thus far been elusive. The present study could potentially have a significant impact on the design of future therapeutic strategies aimed at eradicating HIV in patients receiving effective antiviral therapy for extended periods of time. Considering that reactivation of latently infected, resting $\mathrm{CD}^{+} \mathrm{T}$ cells contributes to the persistence of HIV and initiation of new infection cycles, coadministration of an effective and safe reagent that dampens cellular activation could minimize the spread of virions to uninfected bystander cells (34). In addition, given the persistence of HIV in activated $\mathrm{CD} 4^{+} \mathrm{T}$ cells in patients receiving effective antiviral therapy without detectable plasma viremia, intensification of existing drug regimens or the addition of a new class of drug, such as HIV entry inhibitors, in aviremic patients may be necessary to abrogate the low but detectable levels of ongoing viral replication originating from this cellular compartment.

\section{Methods}

Study subjects. Eleven HIV-infected individuals (mean CD4 ${ }^{+} \mathrm{T}$ cell count 623 per $\mathrm{mm}^{3}$ blood, range 280-1220; mean $\mathrm{CD}^{+} \mathrm{T}$ cell count 673 per $\mathrm{mm}^{3}$ blood, range 382-1230) who were receiving effective antiviral therapy for an average of 8.3 years (range 7.6-9.1) were studied. None of these patients experienced any detectable plasma viremia after initial suppression of HIV replication following the start of antiviral therapy and at the time of study (lower limit of detection of 50 copies HIV RNA/ml). All patients were receiving various antiviral regimens containing at least 1 protease inhibitor and/or 1 nonnucleoside reverse transcriptase inhibitor in addition to 2 reverse transcriptase inhibitors of HIV. Leukapheresis was conducted in accordance with protocols approved by the Institutional Review Boards of the University of Toronto, Ontario, Canada and the National Institute of Allergy and Infectious Diseases, NIH. Each patient signed a consent form that was approved by the above institutional review boards.

Isolation of $\mathrm{CD}^{+} T$ cells. PBMCs were obtained from leukapheresis by Ficoll-Hypaque density gradient centrifugation. $\mathrm{CD} 4^{+} \mathrm{T}$ cells were isolated from PBMCs of HIV-infected individuals using a columnbased cell separation technique (StemCell Technologies) as previously described (35). In order to isolate resting and activated $\mathrm{CD}^{+}$ $\mathrm{T}$ cells, total $\mathrm{CD}^{+} \mathrm{T}$ cells were labeled with anti-CD3 (APC), CD4 (FITC), CD25 (PE), CD69 (PE), and HLA-DR (PE) antibodies (BD Biosciences). Then, $\mathrm{CD}^{+} \mathrm{CD} 4^{+} \mathrm{CD} 25^{-} \mathrm{CD} 69^{-} \mathrm{HLA}^{-\mathrm{DR}}{ }^{-}$(resting) and $\mathrm{CD}^{+} \mathrm{CD} 4{ }^{+} \mathrm{CD} 25^{+} \mathrm{CD} 69^{+} \mathrm{HLA}-\mathrm{DR}^{+}$(activated) cells were separated using FACSAria (BD Biosciences) to very high purity (>99.0\%).

Quantitative coculture assays. In order to determine the frequency of $\mathrm{CD}^{+}$ T cells carrying replication-competent HIV, high-input quantitative coculture assays were carried out in which multiple wells containing $1 \times 10^{7}$ $\mathrm{CD}^{+} \mathrm{T}$ cells were subjected to activation as described previously (36).

Quantitative real-time PCR for measurements of HIV DNA. In order to determine the frequency of resting $\mathrm{CD}^{+} \mathrm{T}$ cells carrying HIV proviral DNA in infected individuals, real-time PCR was carried out on genomic DNA isolated from $1-2 \times 10^{6}$ purified resting or activated $\mathrm{CD} 4^{+} \mathrm{T}$ cells using the Puregene DNA isolation kit according to the manufacturer's specifications (Gentra Systems). Then $1 \mu \mathrm{g}$ of DNA was used as template for real-time PCR in an iCycler (Bio-Rad Laboratories). The amplification reac- 
tion was carried out in triplicate using $0.5 \mu \mathrm{M}$ primers, $0.2 \mu \mathrm{M}$ fluorescent probe, $0.8 \mathrm{mM}$ dNTPs, $5 \mathrm{mM} \mathrm{MgCl}_{2}$, and 2.5 U Platinum Taq Polymerase (Invitrogen Corp.) in $50 \mu \mathrm{l}$ total volume. The following primers were used: 5'-GGTCTCTCTGGTTAGACCAGAT-3' (5' primer) and 5'-CTGCTAGAGATTTTCCACACTG-3' (3' primer) along with the fluorescent probe 5'-6FAM-AGTAGTGTGTGCCCGTCTGTT-TAMRA-3'. PCR conditions consisted of a denaturation step at $95^{\circ} \mathrm{C}$ for 3 minutes followed by 45 cycles of 15 seconds at $95^{\circ} \mathrm{C}$ and 1 minute at $58^{\circ} \mathrm{C}$. Serially diluted ACH-2 DNA was also subjected to the above PCR to obtain standard curves.

Quantitation of cell-free HIV virions. Spontaneous release of HIV virions from $6 \times 10^{6}$ bead-separated resting and activated $\mathrm{CD} 4^{+} \mathrm{T}$ cells (Miltenyi Biotech) was quantitated following a 16 -hour incubation in the absence of any activating stimuli. Culture supernatants were then harvested, and cellfree HIV was quantified using the Amplicor HIV-1 Monitor Test (Version 1.5, detection limit 50 copies/ml; Roche Diagnostics Corp.) according to the manufacturer's instructions.

Sequencing of HIV env isolated from resting and activated $C D 4^{+} T$ cells. HIV DNA was amplified to single copy by limiting dilution PCR. First-round primers were ED5 (5'-ATGGGATCAAAGCCTAAAGCCATGTG-3', nucleotides 6556 to 6581, HIV-1 HXB2) and ED12 (5'-AGTGCTTCCTGCTGCTCCCAAGAACCCAAG-3', nucleotides 7822 to 7792, HIV-1 HXB2). Second-round reactions consisted of $1 \mu \mathrm{l}$ of the first-round product as template and primers DR7 (5'-TCAACTCAACTGCTGTTAAATGGCAGTCTAGC-3', nucleotides 6989 to 7020, HIV-1 HXB2) and DR8 (5'-CACTTCTCCAATTGTCCCTCATATCTCCTCC-3', nucleotides 7637 to $7667, \mathrm{HIV}-1$ HXB2) as previously described (9). The final PCR products (650 base pairs) spanning the $\mathrm{C} 2$ to V5 region of the HIV env were ligated into the sequencing vector $\mathrm{PCR} 4-\mathrm{TOPO}$ (Invitrogen Corp.), followed by transformation, amplification, and sequencing.

Phylogenetic trees and cladistic analysis of viral migration. HIV env sequences isolated from resting and activated $\mathrm{CD} 4^{+} \mathrm{T}$ cells of 5 patients were aligned using CLUSTAL W (19) followed by manual adjustment where necessary using the program MacClade (version 3; Sinauer Associates Inc.). Likelihood ratio tests (LRT) $(20,21)$ were performed to establish a maximum-likelihood model of viral evolution that was statistically consistent with the data while making the fewest number of assumptions about the evolution of the sequences themselves (22). Parameters derived from the best-fit model were then applied to the datasets to obtain maximum-likelihood trees using the program PAUP* (version 4.0b10; Sinauer Associates Inc.). In order to obtain maximum-likelihood trees, 10 random addition replicates were performed using the most exhaustive branch-swapping algorithm (tree bisection-reconnection).
A cladistic method (23) was used to investigate whether virologic crosstalk occurred between the resting and activated $\mathrm{CD} 4{ }^{+} \mathrm{T}$ cell compartments. If no viral crosstalk took place between these 2 cellular compartments, one would expect a single common ancestor for these 2 cellular compartments. The estimated maximum likelihood phylogenetic tree was used to map the number of potential migration events using parsimony (MacClade). Specifically, 2 state characters were created so that sequences derived from activated and resting $\mathrm{CD} 4^{+} \mathrm{T}$ cells were assigned to 1 and 2 , respectively. The number of transitions from state 1 to state 2 or the reverse in each phylogenetic tree was then recorded. If all sequences in 1 cellular compartment were monophyletic, the maximum number of character state changes would equal 1 in one direction and 0 in the other. If, however, sequences from one cellular compartment were more closely related to those from the other cellular compartment, the number of character state changes would increase. As a result, the most parsimonious estimate of the minimum number of viral exchanges between the 2 cellular compartments is predicated on the basis of the estimated maximum likelihood phylogenetic tree.

Statistics. Differences in the levels of HIV-1 proviral DNA in resting and activated $\mathrm{CD} 4{ }^{+} \mathrm{T}$ cells were tested for significance by the Wilcoxon signed-rank test.

\section{Acknowledgments}

We thank the patients for their participation in this study. We also thank Roberta Halpenny, Victoria Govan, and Leonard Noay as well as the staff of the National Institute of Allergy and Infectious Diseases HIV Clinic for their invaluable assistance in the execution of this study. This research was supported by the Intramural Research Program of the National Institute of Allergy and Infectious Diseases, NIH.

Received for publication July 7, 2005, and accepted in revised form August 23, 2005.

Address correspondence to: Tae-Wook Chun, Laboratory of Immunoregulation, National Institute of Allergy and Infectious Diseases, National Institutes of Health, Building 10, Room 6A32, 9000 Rockville Pike, Bethesda, Maryland 20892, USA. Phone: (301) 496-0890; Fax: (301) 402-5920; E-mail: twchun@nih.gov.

Tae-Wook Chun and David C. Nickle contributed equally to this work.
1. Department of Health and Human Services Public Health Service. 2000. HIV/AIDS surveillance report. Centers for Disease Control and Prevention. 12:1-44.

2. Chun, T.W., et al. 1997. Presence of an inducible HIV-1 latent reservoir during highly active antiretroviral therapy. Proc. Natl. Acad. Sci. U. S. A. 94:13193-13197.

3. Finzi, D., et al. 1997. Identification of a reservoir for HIV-1 in patients on highly active antiretroviral therapy. Science. 278:1295-1300.

4. Wong, J.K., et al. 1997. Recovery of replicationcompetent HIV despite prolonged suppression of plasma viremia. Science. 278:1291-1295.

5. Siliciano, J.D., et al. 2003. Long-term follow-up studies confirm the stability of the latent reservoir for HIV-1 in resting CD4+ T cells. Nat. Med. 9:727-728

6. Zhang, L., et al. 1999. Quantifying residual HIV-1 replication in patients receiving combination antiretroviral therapy. N. Engl. J. Med. 340:1605-1613.

7. Furtado, M.R., et al. 1999. Persistence of HIV-1 transcription in peripheral-blood mononuclear cells in patients receiving potent antiretroviral therapy. N. Engl. J. Med. 340:1614-1622.

8. Hermankova, M., et al. 2003. Analysis of human immunodeficiency virus type 1 gene expression in latently infected resting CD4+ T lymphocytes in vivo. J. Virol. 77:7383-7392.

9. Chun, T.W., et al. 2000. Relationship between pre-existing viral reservoirs and the re-emergence of plasma viremia after discontinuation of highly active anti-retroviral therapy. Nat. Med. 6:757-761.

10. Ramratnam, B., et al. 2000. The decay of the latent reservoir of replication-competent HIV-1 is inversely correlated with the extent of residual viral replication during prolonged anti-retroviral therapy. Nat. Med. 6:82-85.

11. Zhu, T., et al. 2002. Evidence for human immunodeficiency virus type 1 replication in vivo in $\mathrm{CD} 14(+)$ monocytes and its potential role as a source of virus in patients on highly active antiretroviral therapy. J. Virol. 76:707-716.

12. Ramratnam, B., et al. 2004. Intensification of antiretroviral therapy accelerates the decay of the HIV-1 latent reservoir and decreases, but does not elimi- nate, ongoing virus replication. J. Acquir. Immune. Defic. Syndr. 35:33-37.

13. Sharkey, M.E., et al. 2000. Persistence of episomal HIV-1 infection intermediates in patients on highly active anti-retroviral therapy. Nat. Med. 6:76-81.

14. Sharkey, M., Triques, K., Kuritzkes, D.R., and Stevenson, M. 2005. In vivo evidence for instability of episomal human immunodeficiency virus type 1 cDNA. J. Virol. 79:5203-5210.

15. Natarajan, V., et al. 1999. HIV-1 replication in patients with undetectable plasma virus receiving HAART. Lancet. 353:119-120.

16. Patterson, B.K., et al. 2001. Persistence of intracellular HIV-1 mRNA correlates with HIV-1-specific immune responses in infected subjects on stable HAART. AIDS. 15:1635-1641.

17. Havlir, D.V., et al. 2003. Productive infection maintains a dynamic steady state of residual viremia in human immunodeficiency virus type 1 -infected persons treated with suppressive antiretroviral therapy for five years. J. Virol. 77:11212-11219.

18. Chun, T.W., et al. 2003. Gene expression and viral prodution in latently infected, resting CD $4+\mathrm{T}$ cells 
in viremic versus aviremic HIV-infected individuals. Proc. Natl. Acad. Sci. U. S. A. 100:1908-1913.

19. Thompson, J.D., Higgins, D.G., and Gibson, T.J. 1994. CLUSTAL W: improving the sensitivity of progressive multiple sequence alignment through sequence weighting, position-specific gap penalties and weight matrix choice. Nucleic Acids Res. 22:4673-4680

20. Huelsenbeck, J.P., and Crandall, K.A. 1997. Phylogeny estimation and hypothesis testing using maximum likelihood. Annu. Rev. Ecol. Syst. 28:437-466.

21. Huelsenbeck, J.P., and Rannala, B. 1997. Phylogenetic methods come of age: testing hypotheses in an evolutionary context. Science. 276:227-232.

22. Posada, D., and Crandall, K.A. 1998. MODELTEST: testing the model of DNA substitution. Bioinformatics. 14:817-818.

23. Slatkin, M., and Maddison, W.P. 1989. A cladistic measure of gene flow inferred from the phylogenies of alleles. Genetics. 123:603-613.

24. Perelson, A.S., Neumann, A.U., Markowitz, M., Leonard, J.M., and Ho, D.D. 1996. HIV-1 dynamics in vivo: virion clearance rate, infected cell life-span, and viral generation time. Science. 271:1582-1586.

25. Perelson, A.S., et al. 1997. Decay characteristics of HIV-1-infected compartments during combination therapy. Nature. 387:188-191.

26. Bukrinsky, M.I., Stanwick, T.L., Dempsey, M.P., and Stevenson, M. 1991. Quiescent T lymphocytes as an inducible virus reservoir in HIV-1 infection. Science. 254:423-427.

27. Chun, T.W., et al. 1997. Quantification of latent tissue reservoirs and total body viral load in HIV-1 infection. Nature. 387:183-188.

28. Chun, T.W., and Fauci, A.S. 1999. Latent reservoirs of HIV: obstacles to the eradication of virus. Proc. Natl. Acad. Sci. U. S. A. 96:10958-10961.

29. Zhang, L., et al. 2000. Genetic characterization of rebounding HIV-1 after cessation of highly active antiretroviral therapy. J. Clin. Invest. 106:839-845.

30. Kulkosky, J., et al. 2002. Intensification and stimulation therapy for human immunodeficiency virus type 1 reservoirs in infected persons receiving virally suppressive highly active antiretroviral therapy. J. Infect. Dis. 186:1403-1411.

31. Wang, F.X., et al. 2005. IL-7 is a potent and pro- viral strain-specific inducer of latent HIV-1 cellular reservoirs of infected individuals on virally suppressive HAART. J. Clin. Invest. 115:128-137. doi:10.1172/JCI200522574.

32. Stanley, S.K., et al. 1996. Effect of immunization with a common recall antigen on viral expression in patients infected with human immunodeficiency virus type 1. N. Engl. J. Med. 334:1222-1230.

33. Chun, T.W., Engel, D., Mizell, S.B., Ehler, L.A., and Fauci, A.S. 1998. Induction of HIV-1 replication in latently infected CD4+ T cells using a combination of cytokines. J. Exp. Med. 188:83-91.

34. Chapuis, A.G., et al. 2000. Effects of mycophenolic acid on human immunodeficiency virus infection in vitro and in vivo. Nat. Med. 6:762-768.

35. Chun, T.W., et al. 1998. Early establishment of a pool of latently infected, resting CD4 $(+) \mathrm{T}$ cells during primary HIV-1 infection. Proc. Natl. Acad. Sci. U.S. A. 95:8869-8873.

36. Chun, T.W., et al. 1999. Effect of interleukin-2 on the pool of latently infected, resting CD4+ T cells in HIV-1-infected patients receiving highly active anti-retroviral therapy. Nat. Med. 5:651-655. 